\title{
Effect of Testosterone on Lead Acetate Toxicity in Male Albino Rats
}

\author{
Nazar Mohammed Shareef Mahmood \\ General Directorate of Education, Duhok, \\ Ministry of Education, Kurdistan Region, \\ Iraq \\ nazar.mahmood@yahoo.com
}

\author{
Sarkawt Hamad Ameen Hamad \\ Biology Department, \\ Soran University, Iraq \\ sarkawt.hamad@soran.edu.iq
}

\author{
Dlshad Hussein Hassan \\ Biology Department, \\ Soran University, Iraq \\ dlshad.hussein@gmail.com
}

\author{
Karwan Ismael Othman \\ Biology Department, \\ Soran University, Iraq
}

karwan.othman@soran.edu.iq

\begin{abstract}
The toxicity of lead acetate (L. A.) concerned to public health disruptor due to its persistence in the environment and it has the adverse influence on the human and animal health as well. It causes physiological,biochemical, and neurological dysfunctions in humans. Histologically it has a negative effect on the liver which is considered one of the major target organs where acts as detoxification machine by elimination the toxic substance from the blood in rich with it. As well as it affects kidneys that are the two of the most filtering organs. Therefore the present study was aimed to investigate the histopathological effect of L.A. on liver and kidney tissues in male rats. Twenty male rats involved in the study were equally and randomly divided into two groups each of them involved 10 animals. Group I (castrated rats) and Group II (control) each group received $80 \mathrm{mg} / \mathrm{L}$ of lead acetate dissolved in one liter distilled water by drinking for 15 days. Histological sections showed some alterations including abnormal architecture, cell degeneration, nuclear degeneration, hyperchromatic hepatocytes, immune cells, degeneration in tubules, dilation in sinusoids, dilation in central vein of liver increased bowman's space glomerular atrophy degeneration of tubular cells in liver and kidney tissues of rats in castrated rats from control group. But the size of degenerated tissue was more severe in castrated male rats. It was concluded that the castration process could produce a hypogonadism and decreased testosterone which owns many receptors in kidney and liver may produce adverse influence with L.A. administration.
\end{abstract}

Keywords: Lead acetate, liver, kidney, Castration and Testosterone.

\section{INTRODUCTION}

Lead could be found in our food, water, air and soil. It is emitted by smelters and boilers that burn motor oil are frequently deposited in the soil, where it is taken up by crops [1]. Also it is known as an enzymatic toxicant, it is neurotoxic, hematological and cardiovascular toxic, nephrotoxic, immunotoxic, carcinogenic, teratogenic and mutagenic [2].

\section{LITERATURE REVIEW}

It has been reported that Lead could interfere with environment because of wide applications for making pipes, paints, enamels and glazes [3]. One study suggested that the chronic exposure to high levels of lead caused adverse effect on renal function in animals [4]. Also rats were given $1 \mathrm{mg}$ L.A. for four weeks caused lipid peroxidation in kidney [5]. Besides that it caused mitochondrial configuration changes [6]. On one hand chronic exposure to lead produced significant histological and histochemical changes in the liver of the wistar albino rats [7]. On the other hand lead is capable of damaging the organism in many ways due to its high affinity to various tissues [8]. Therefore hepatotoxicity and nephrotoxicity are known to occur in persons with exposure to heavy metals. Previous autopsies studies of lead exposed humans showed that liver tissue is the largest repository $33 \%$ of lead among the soft tissue followed by kidney cortex and medulla [9]. Also histological studies showed that mice were exposed to the L.A. showed dramatical abnormal changes in the liver and kidney [10]. In an attempt the histological study showed that lead can induce several alterations such as hypertrophy of hepatocytes, portal space and central vein dilatation, vacuolation and lymphocytic infiltration [11]. Meanwhile chronic exposure to lead imposes a potent toxic effect on liver cells manifested as glycogen depletion, cellular infiltration and liver architecture in the form of initiation of periportal fibrosis that may progress to liver cirrhosis [12]. Furthermore it has been suggested that mice were treated with lead acetate $(10 \mathrm{mg} / \mathrm{kg})$ dissolved in $0.02 \mathrm{ml}$ of distill water decreased in cortical thickness of kidney significantly [13]. In men, testosterone is produced in the lydig cell of the testis [14], and it functions in the development of secondary sex characters (voice thickening, increase in power and hiring), release of gonadotropin and functions anabolic ally in the stimulation of protein synthesis, also it is found in the body in three forms as free, SHBG (Sex Hormone-binding Globulin) and those that are impotently bended to albumin or cortisol binding globulin [15]. Besides that hypogonadism is a clinical condition in which low levels of serum testosterone are found in association with specific signs and symptoms. When hypogonadism occurs in an older man, the condition is often called andropause or androgen deficiency of the aging 
male or late onset hypogonadism [16]. Previous study showed that castration increased lipid peroxidation and consequently reduced glutathione in both liver and kidney [17]. Therefore, the aim of the present study was to show the influence of L. A. on liver and kidney tissue in castrated male rats.

\section{MATERIALS AND METHODS}

\subsection{Experimental animals}

The rats (Rattus norvegicus) were inbred in the animal house of Biology department, Faculty of Science, Soran University, Iraq. Their body weights ranged between (250 - 370) grams (g), the animals acclimatized in an environmentally controlled room at constant temperature $22 \pm 2{ }^{\circ} \mathrm{C}$, on a lighting schedule $12 \mathrm{~h}$ light and $12 \mathrm{~h}$.

\subsection{Castration}

Rat were anaesthetized by injection a mixture of Ketamine hydrochloride ( $80 \mathrm{mg} / \mathrm{Kg}$ ) and Xylazine (12 $\mathrm{mg} / \mathrm{Kg}$ ) intraperitoneally; a small incision $(1-2 \mathrm{~cm})$ was done on the frontal aspect of scrotum, then testes pulled out gently without bleeding, near abdomen the blood vessels and ducts tightly ligated by absorbable suture (DemTech, England), then after cut testes sterilized with Hibitane (5\%), and scrotum sewed by Nylon mono filament; all steps were performed for sham group without touching the testes.

\subsection{Lead acetate dose preparation}

Dose of L.A. was prepared by dissolving $80 \mathrm{~g}$ of L.A. (Spain) in 1 liter of distil water and put into bottles were given to rats replaced with water as ad libitum.

\subsection{Design of the experimental}

Twenty adult male rats weighing (250-370) gm were randomly and equally divided into two groups, each group containing 10 males, and each five rats were caged in one plastic for 15 days. Group I (castrated): their testes removed surgically and given $80 \mathrm{mg} / \mathrm{L}$ of L.A. by drinking.

Group II (control): their scrotum were opened and sewed without touching the tests and they were given $80 \mathrm{mg} / \mathrm{L}$ of L.A. by drinking.

\subsection{Anesthesia}

After fasting for $24 \mathrm{~h}$ the rats were anesthetized by a combination of ketamine (Rotexmedica and Tritta Germany) and xylazine (Xyla Ject Holland). Ketamine and xylazine were injected intraperitoneally in a dose of $90 \mathrm{mg} / \mathrm{kg}$ and $10 \mathrm{mg} / \mathrm{kg} \mathrm{BW}$ respectively [18]. After 10 min a state of anesthesia was reached. Supplementary small doses of the combination were given as necessary to maintain the level of anesthesia. Dissection and removal of the organs. Animals were dissected then the liver and right kidney were removed then fixed in $10 \%$ formalsaline.

\subsection{Histological sectioning}

Preserved tissue samples from fixative solution exposed to serial processes began with dehydration, clearing and impregnation using a series of graded ethanol in ascending concentrations then immersed in xylene. Finally embedded in paraffin wax and cooled
[19]. Paraffin sections were cut by rotary microtome (QPJ-1,) [19]. Then stained with haematoxylin $(\mathrm{H})$ and eosin (E) [20]. Finally photos taken by novel digital microscope in two magnification $400 \mathrm{X}$ and $1000 \mathrm{X}$ with oil (XZS-N107T, China).

\section{RESULTS}

\subsection{Liver}

In the present study the histological sections of the liver treated with L.A. showed some alterations in group I included degeneration and present of multinucleated hepatocytes in the tissue (plate 1), dilated of central vein, degeneration of sinusoids cells (plate 2). Whereas the plates 3 and 4 showed hyperchromatic hepatocytes blood infiltration to central vein. In addition that the Plate 5 showed hyperchromatic hepatocytes presented as well, and empty central vein. While the histological sections of the liver in Group II treated with L.A. showed minimal cellular degeneration involved hyperchromatic hepatocytes and immune cells (plate 6). And normal hepatocytes (plate 7) as well.

\subsection{Kidney}

The histological sections of the kidney in group II treated with L.A. showed some degeneration and abnormal characteristics involved glomerular atrophy and increased lumen of tubule (Plates 8 and 9). While Plates 10 and 11 showed increased Bowman's space and degeneration of tubular cells. Furthermore the plate 12 showed glomerular atrophy and degeneration of tubular cells. Whereas the histological sections of the kidneys in group I treated with L.A. showed some tissue abnormalities involved glomerulus, Bowman's capsule and some immune cells (plate 13).

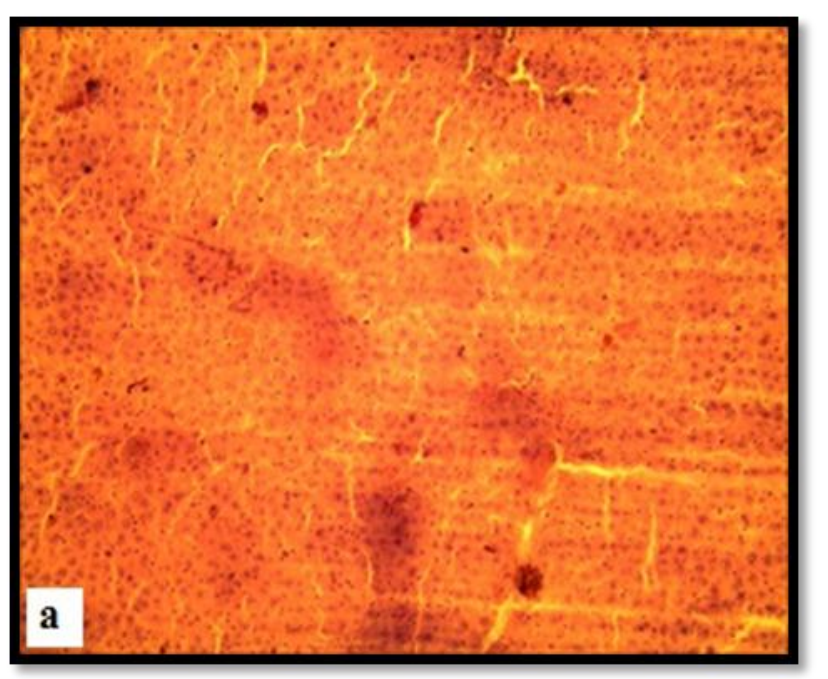




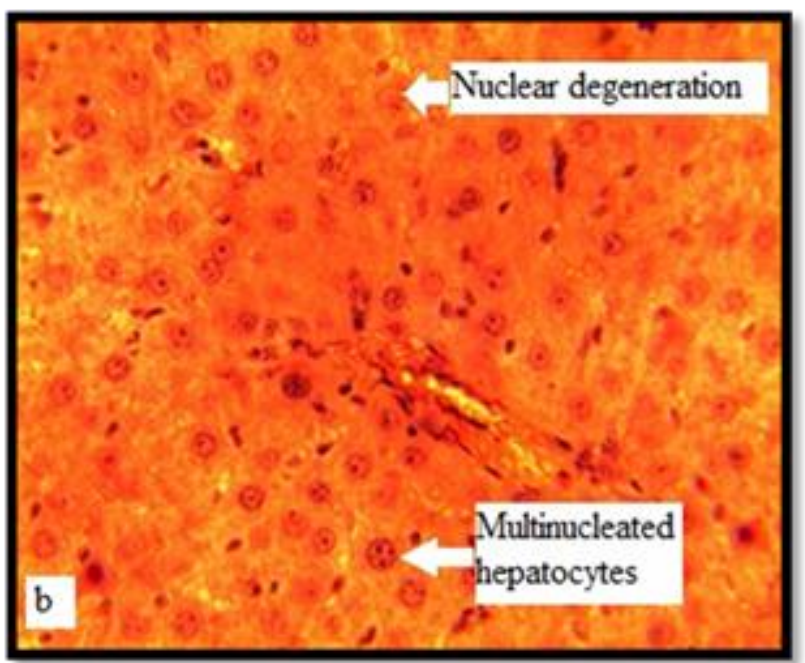

Plate 1 ( $\mathrm{a}$ and $\mathrm{b}$ ): Histological section of liver in group I treated with L.A. showing nuclear degeneration and present of multinucleated hepatocytes (a: 100X, b: 400X, Stain: H.\&E.).
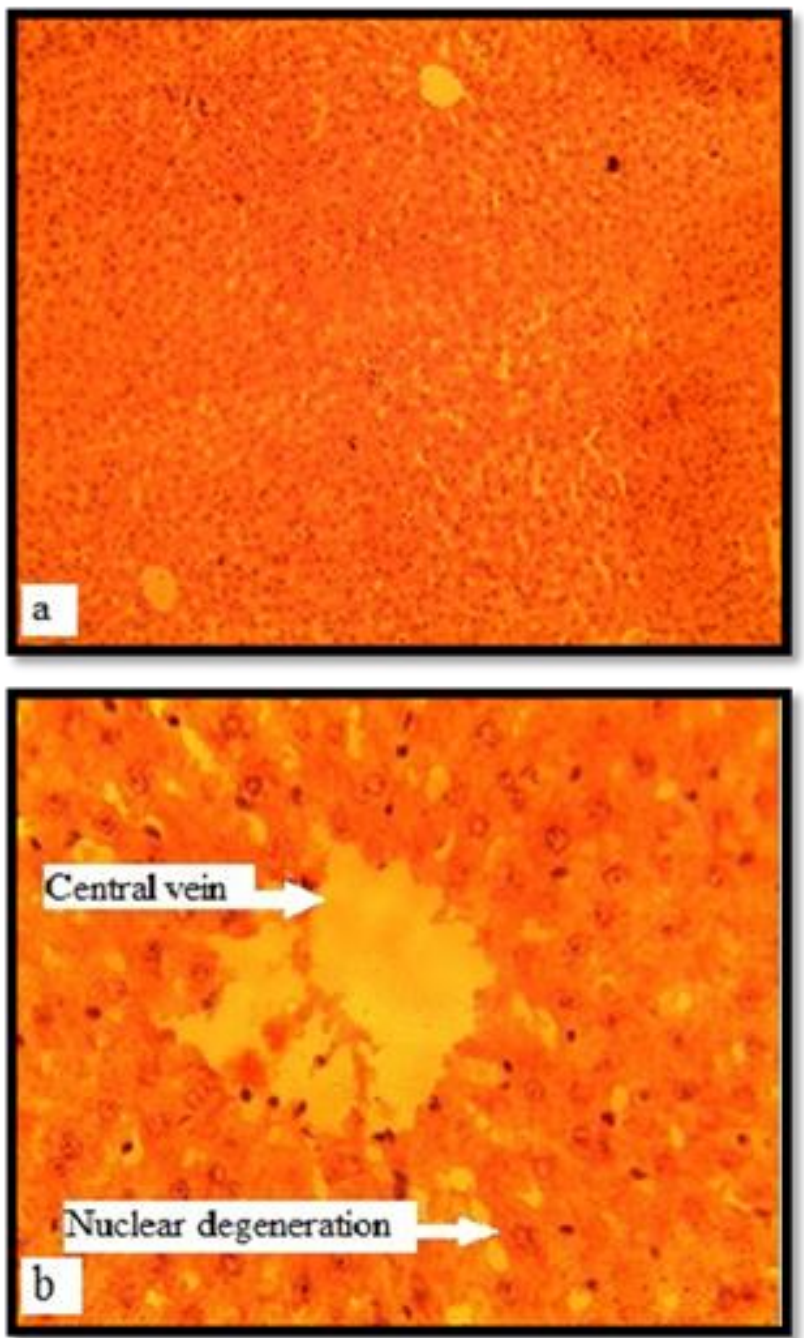

Plate 2 ( $\mathrm{a}$ and $\mathrm{b}$ ): Histological section of liver in group I treated with L.A. showing nuclear degeneration and dilation of central vein. (a: $100 \mathrm{X}$, b: $400 \mathrm{X}$, Stain: H.\&E.).
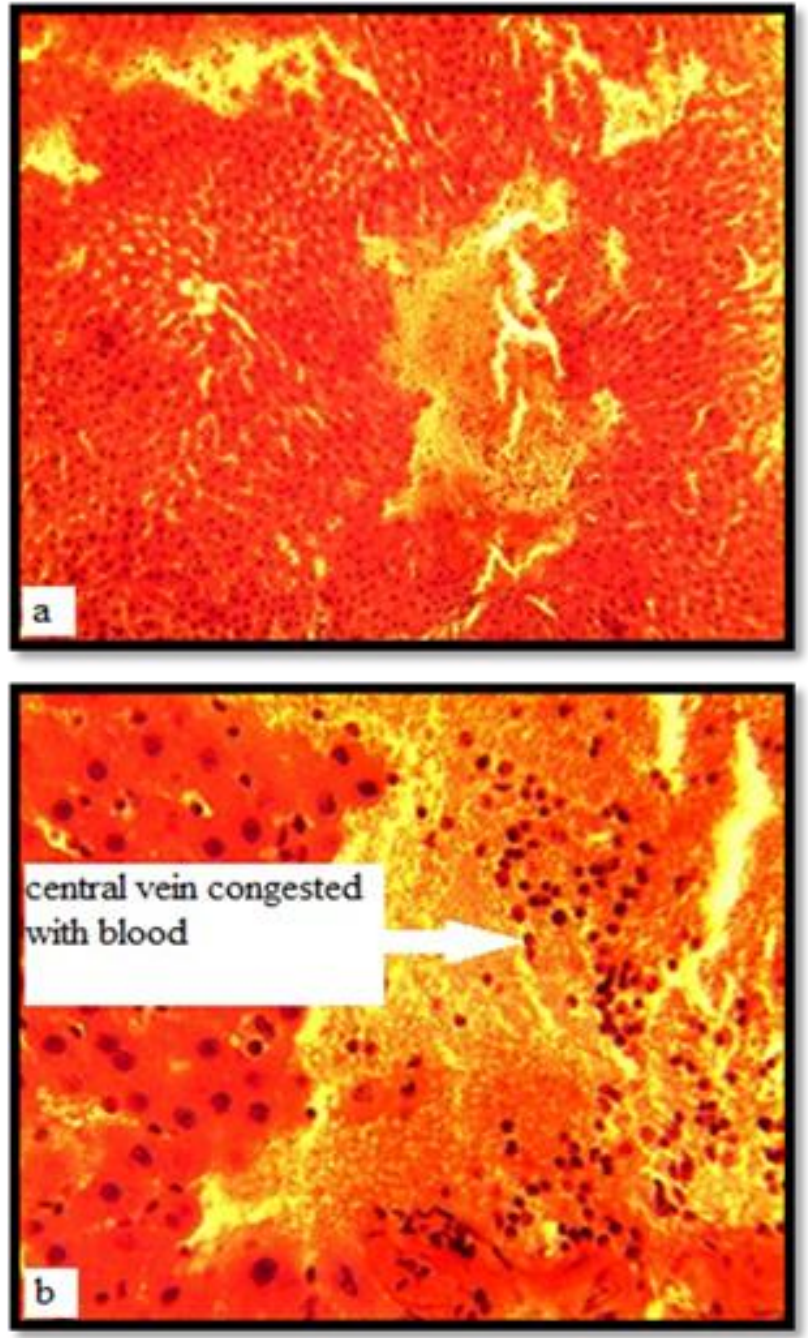

Plate 3 ( $a$ and $b$ ): Histological section of liver in group I treated with L.A. showing hyperchromatic hepatocytes and blood infiltration to central vein. (a: 100X, b: 400X, Stain: H.\&E.).

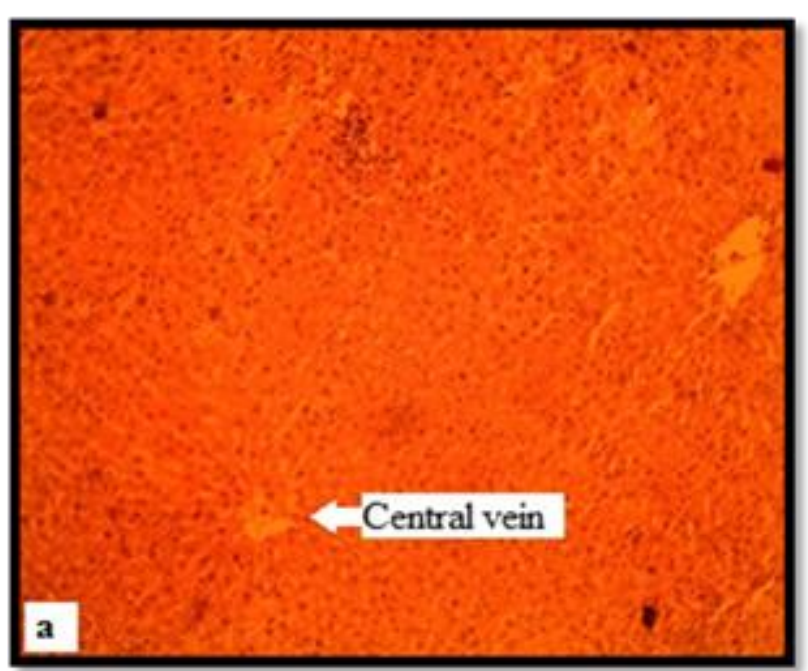




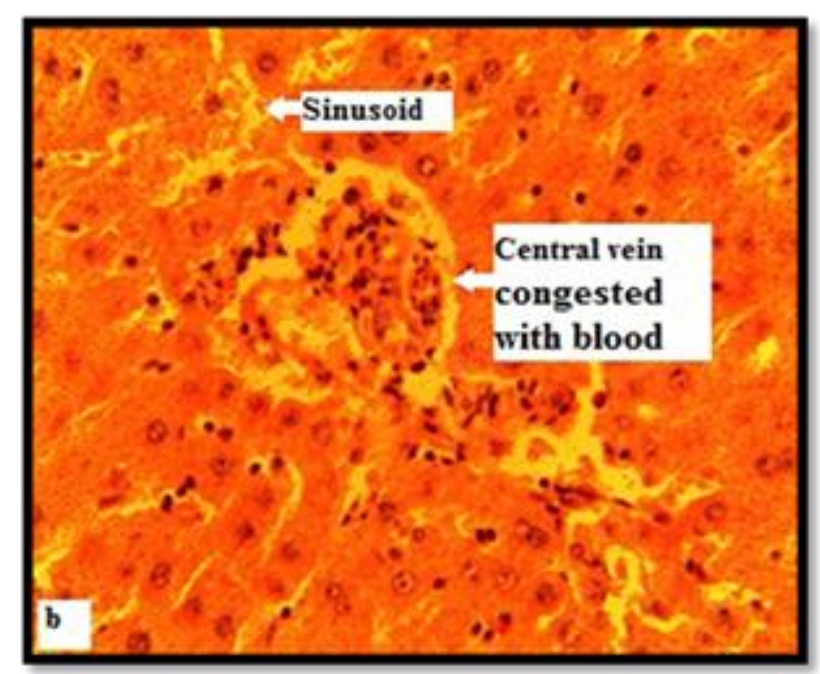

Plate 4 ( $\mathrm{a}$ and $\mathrm{b}$ ): Histological section of liver in group I treated with L.A. showing hyperchromatic hepatocytes and blood infiltration to central vein. (a: 100X, b: 400X, Stain: H.\&E.).
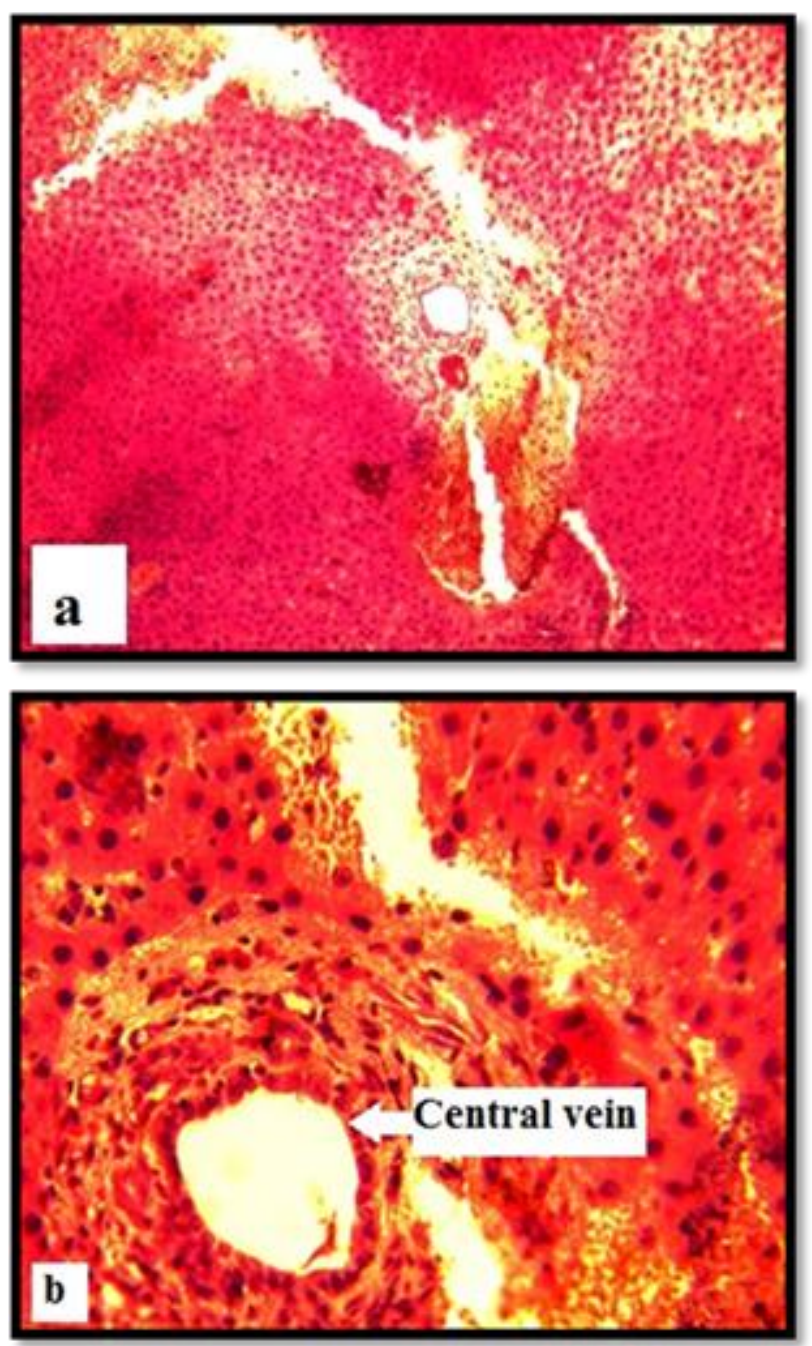

Plate 5 ( $\mathrm{a}$ and $\mathrm{b}$ ): Histological section of liver in group I treated with L.A. showing hyperchromatic hepatocytes and empty central vein. (a: 100X, b: 400X, Stain: H.\&E.).
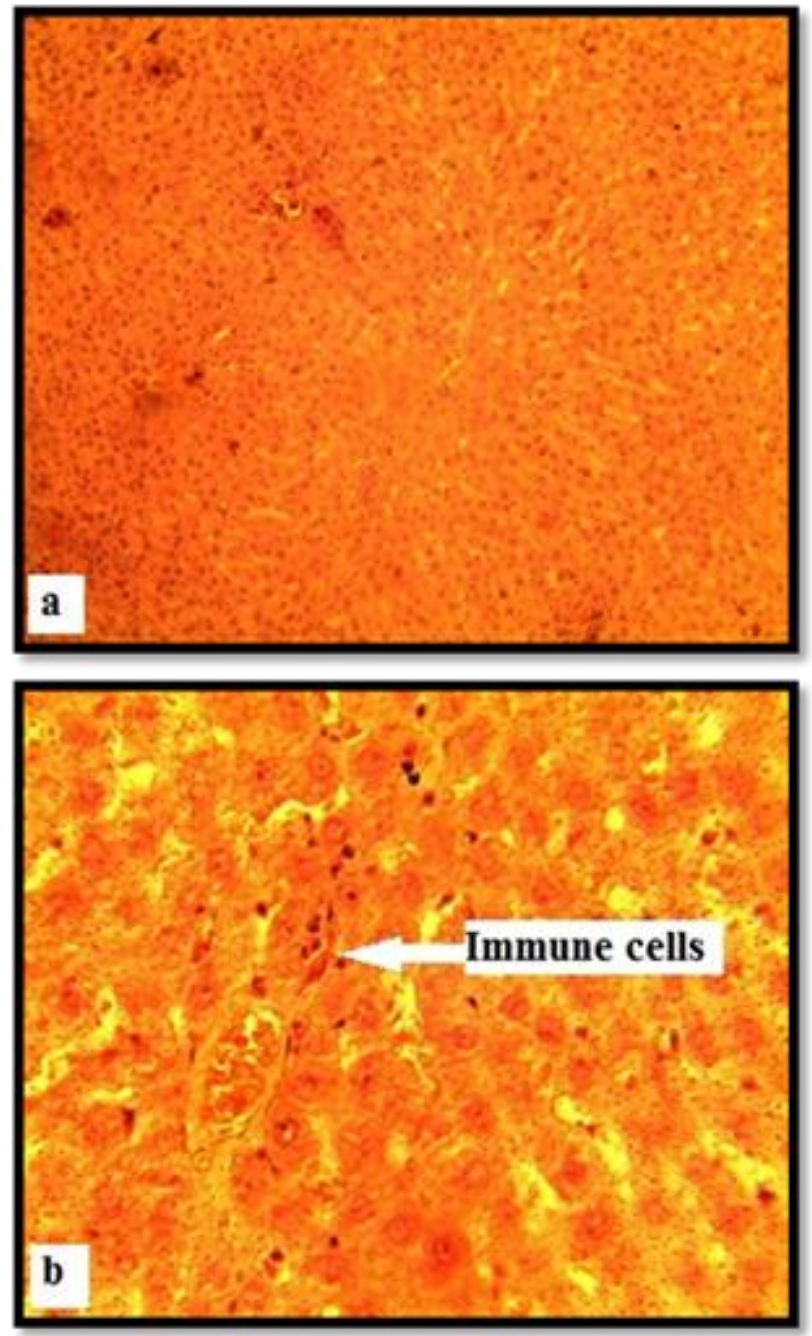

Plate 6 ( $\mathrm{a}$ and $\mathrm{b}$ ): Histological section of liver in group II treated with L.A. showing some dilation of sinusoids and Immune cells. (a: 100X, b: 400X, Stain: H.\&E.).

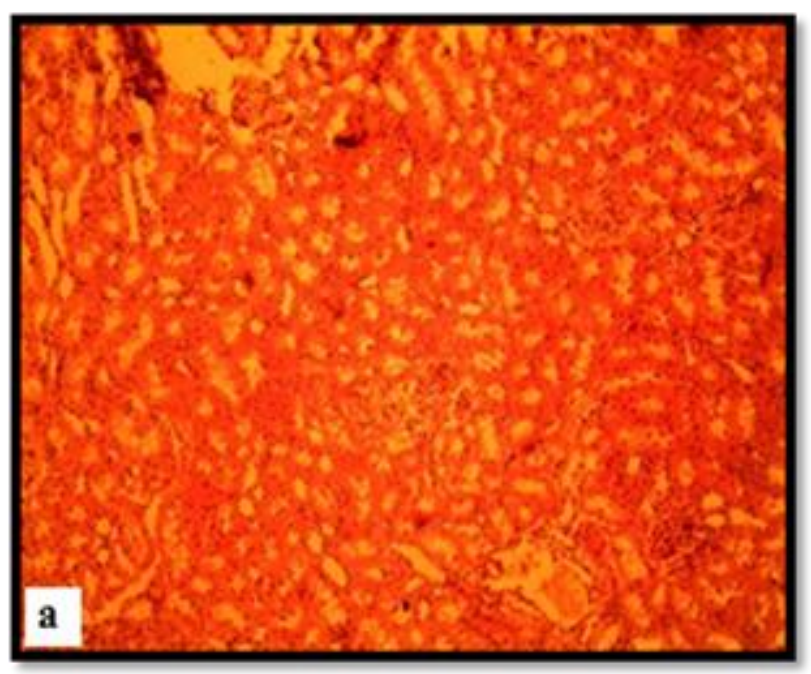




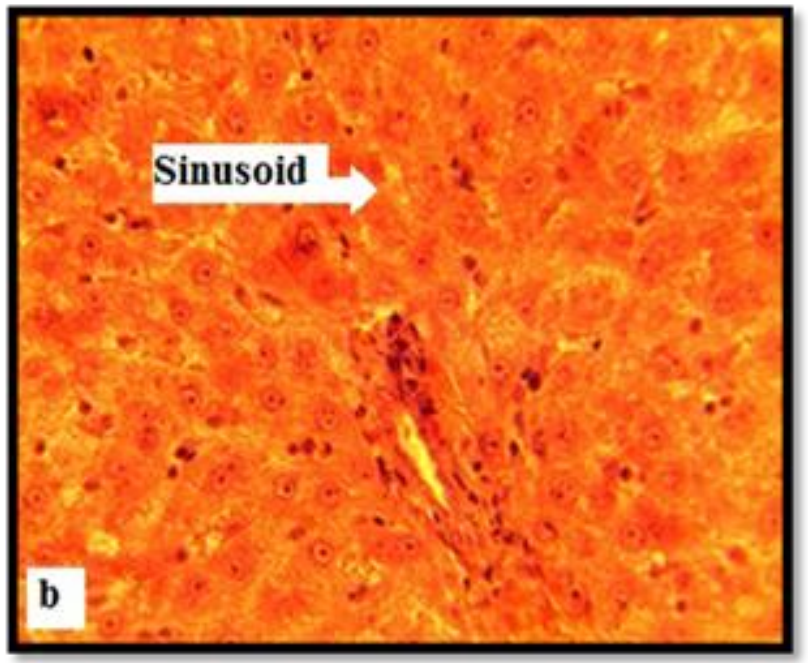

Plate 7 ( $a$ and b): Histological section of liver in group II treated with L.A. showing normal hepatocytes and sinusoids. (a: 100X, b: 400X, Stain: H.\&E.).
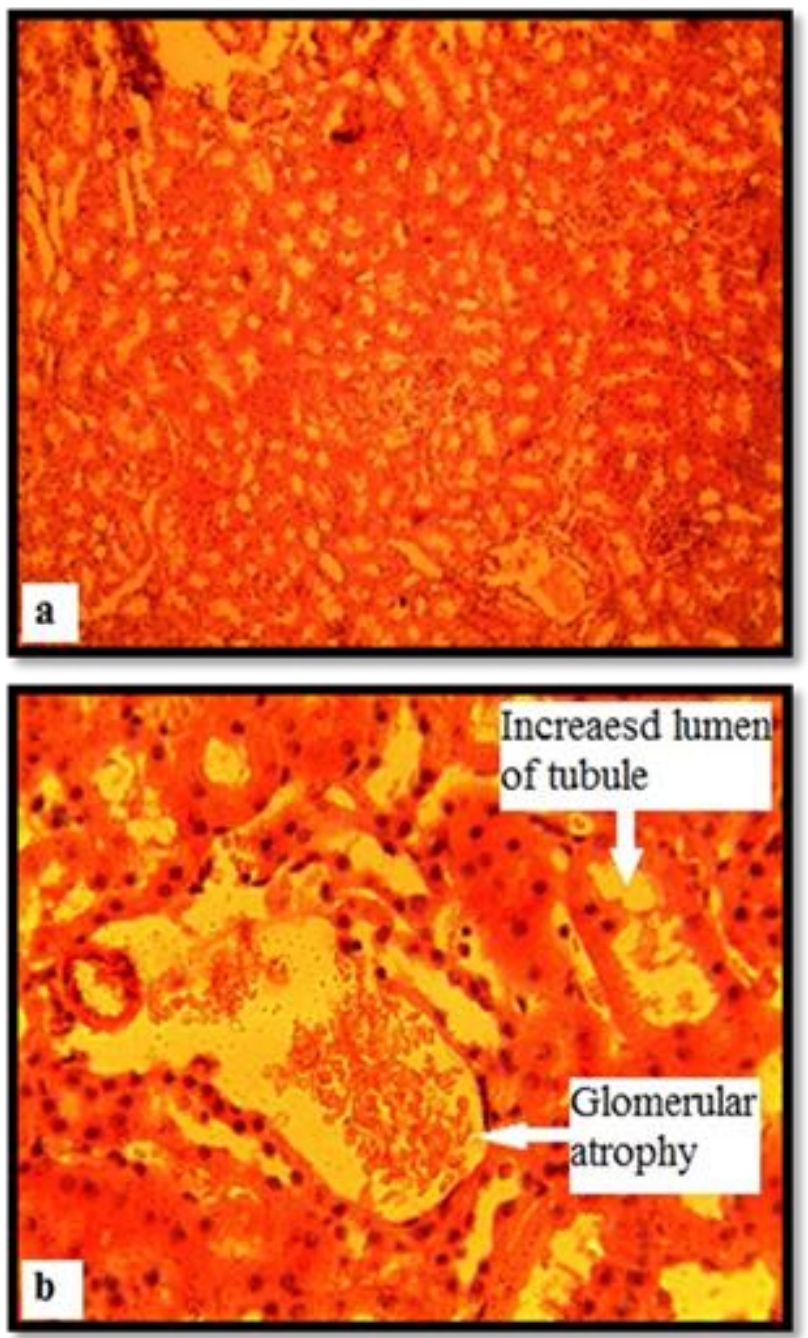

Plate 8 ( $\mathrm{a}$ and $\mathrm{b}$ ): Histological section of kidney in group I treated with L.A. showing glomerular atrophy and increased lumen of tubule . (a: 100X, b: 400X, Stain: H.\&E.).
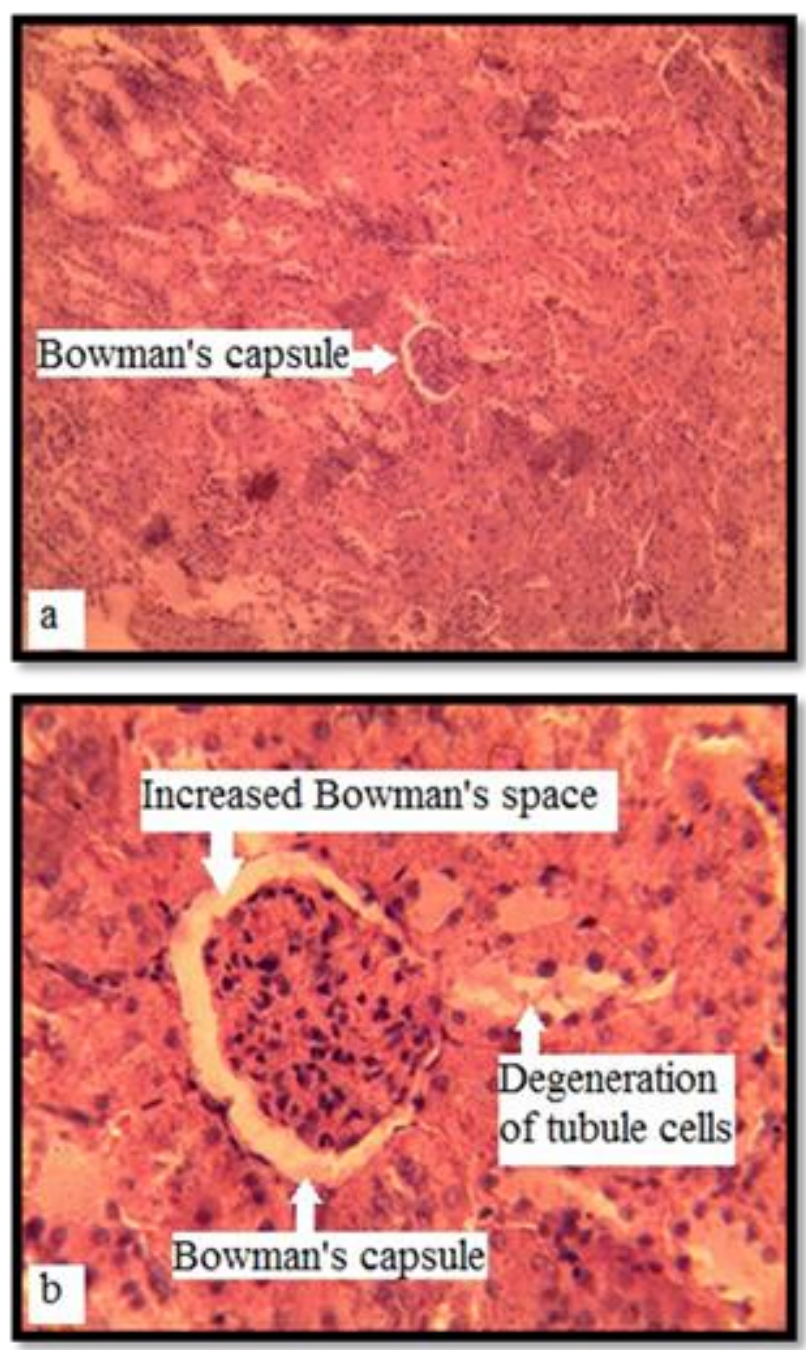

Plate 9 ( $a$ and b): Histological section of kidney in group I treated with L.A. showing Bowman's capsule, increased Bowman's space and degeneration of tubular cells. (a: 100X, b: 400X, Stain: H.\&E.).

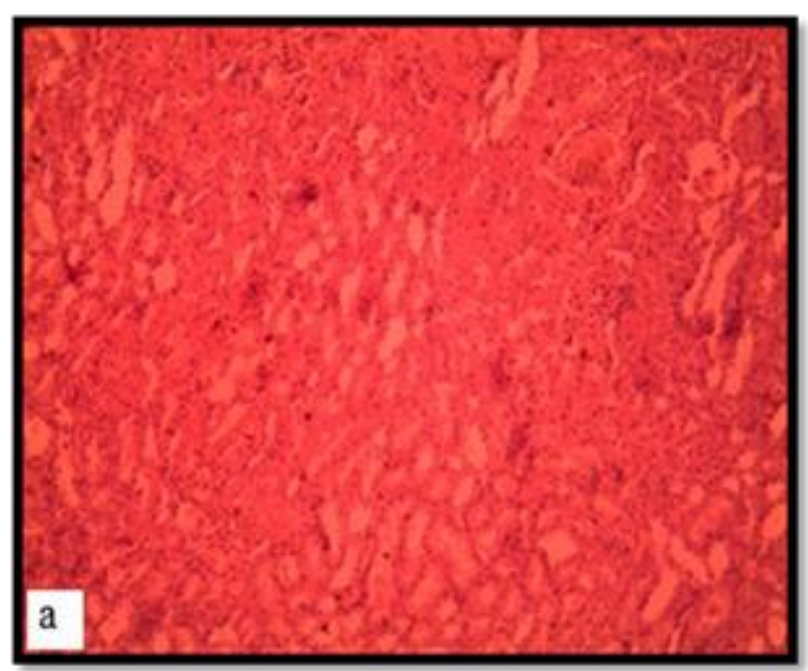




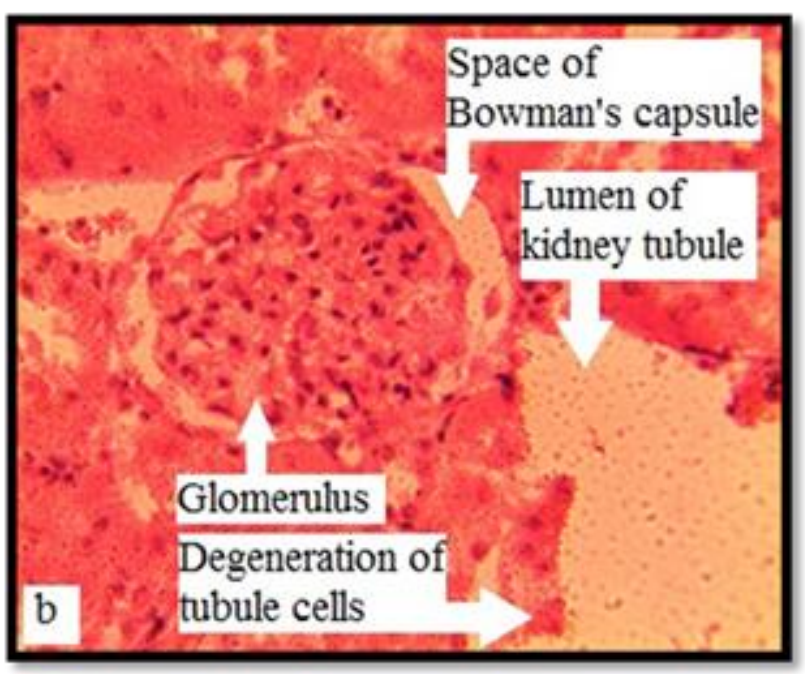

Plate 10 ( $\mathrm{a}$ and $\mathrm{b}$ ): Histological section of kidney in group I treated with L.A. showing Bowman's capsule, increased Bowman's space and degeneration of tubular cells. (a: 100X, b: 400X, Stain: H.\&E.).
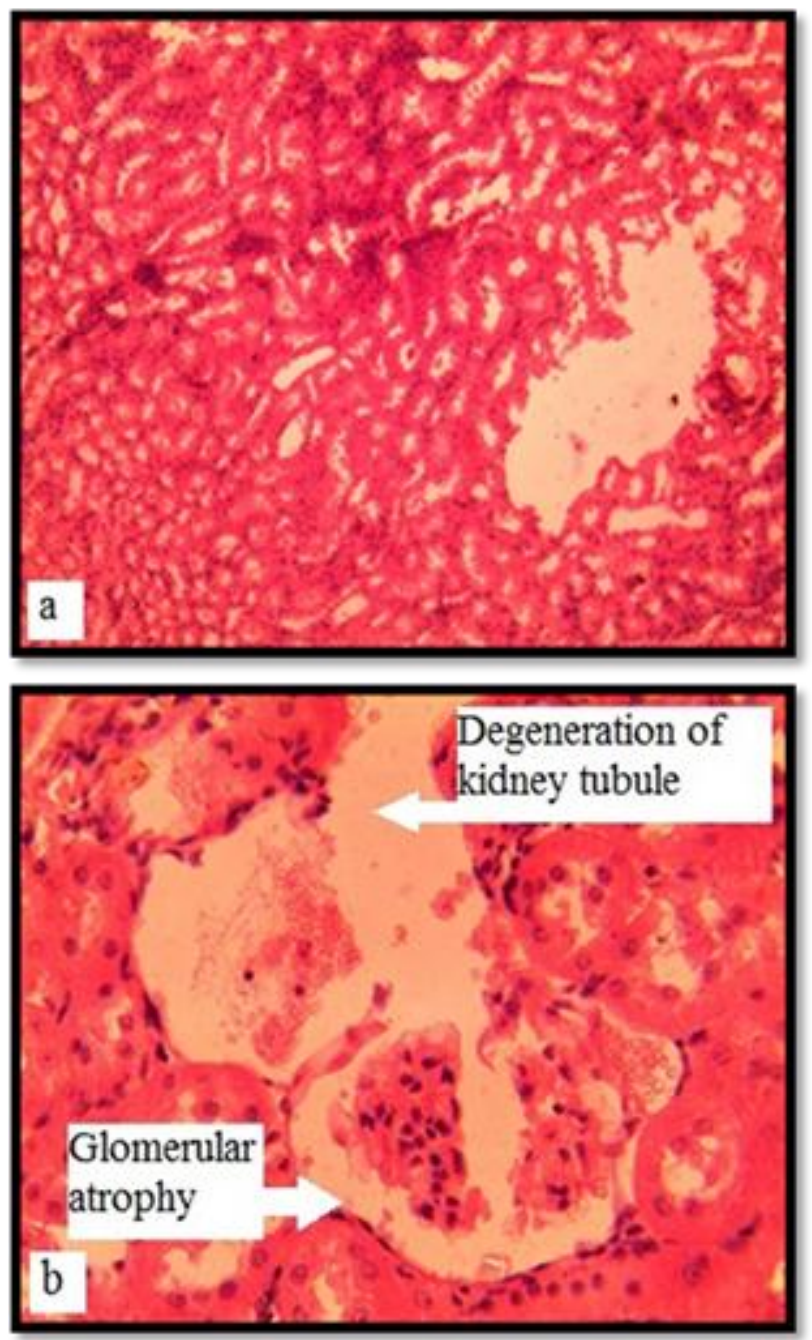

Plate 11 ( $\mathrm{a}$ and $\mathrm{b}$ ): Histological section of kidney in group I treated with L.A. showing glomerular atrophy and degeneration of tubular cells. (a: 100X, b: 400X, Stain: H.\&E.).
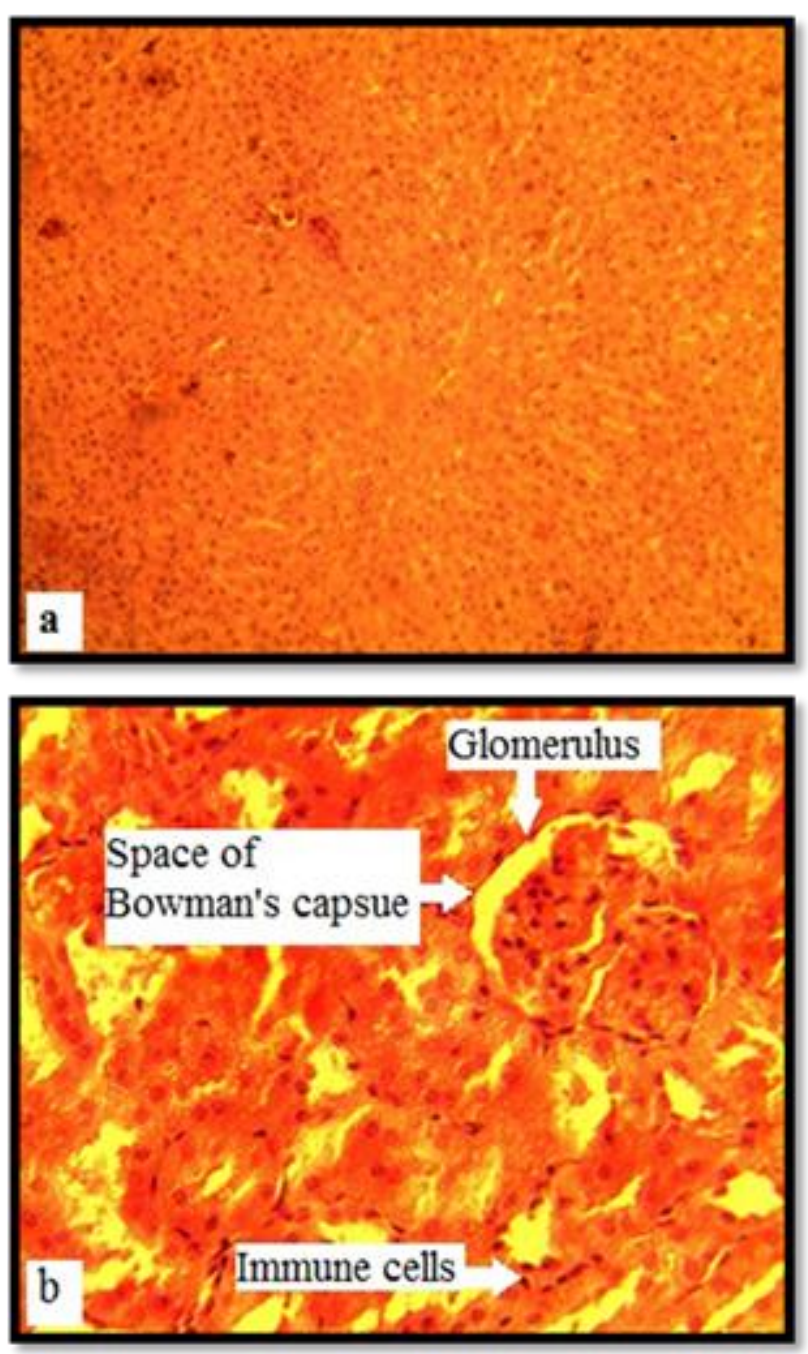

Plate 12 ( $a$ and $b$ ): Histological section of kidney in group II treated with L.A. showing glomerulus, Bowman's capsule and some immune cells. (a: 100X, b: 400X, Stain: H.\&E.).

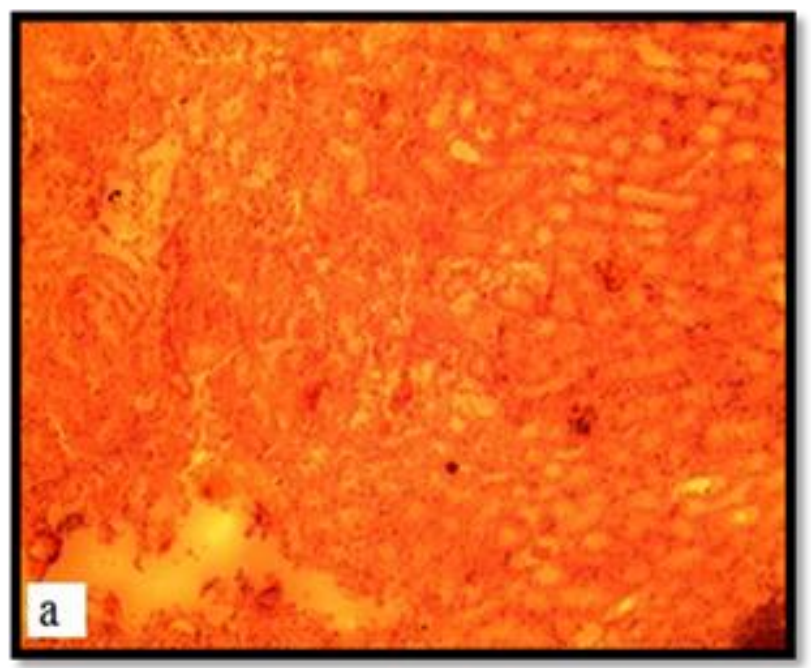




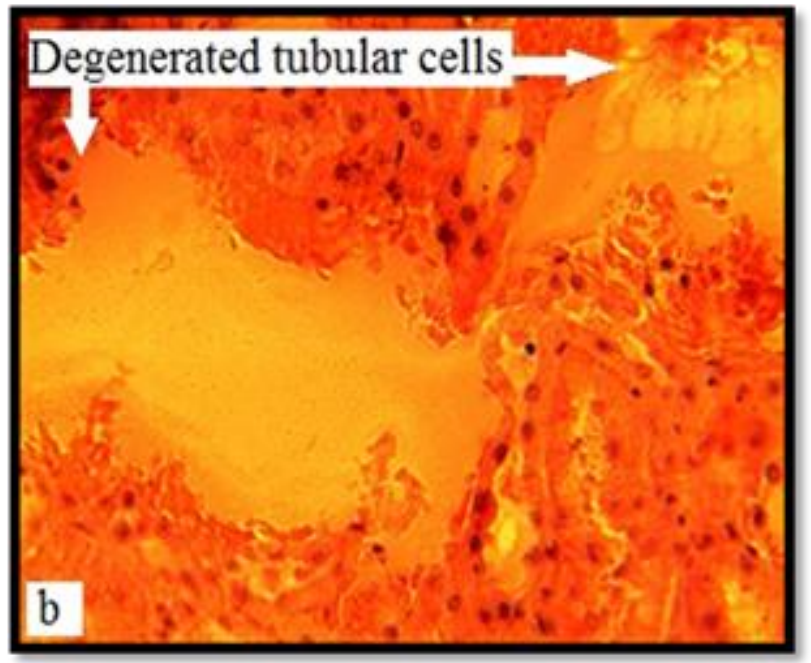

Plate 13 ( $a$ and $b$ ): Histological section of kidney in group II treated with L.A. showing increased lumens of kidney tubules and degeneration of tubular cells. (a: 100X, b: 400X, Stain: H.\&E.).

\section{DISCUSSION}

\subsection{Liver}

It has been reported that when lead is absorbed by the gastrointestinal tract it directly bound with erythrocytes and distributed primarily to soft tissues such as liver [21]. Also It has been showed that liver is recognized as the major organs involved in the storage, biotransformation and detoxification of toxic substances, is of interest in heavy metal poisoning [22]. Besides that the toxicity of L.A. cause free radical formation by generation of reactive oxygen species (ROS), and the direct depletion of antioxidant reserves [23]. Our result is agreed with the findings of [24] who suggested that sinusoidal blood congestion after treatment with lead is an indicator of liver damage. Similar investigations have also been reported by. It is well known that castration in rats causes atrophy of the sexual organs and, to a lesser extent, of other organs. Also it caused a reduction of the liver weight. revealing a powerful hypertrophic effect of the hormone in the liver [25]. Many liver diseases, such as anemia, sarcopenia, bone disease, and gynecomastia are also seen in hypogonadism. On one hand the epidemiological studies have demonstrated that hepatocellular carcinoma (HCC) is more common in men than women, and patient survival from unrespectable $\mathrm{HCC}$ is worse in men. According to previous finding and our result, the lack of testes and testosterone hormone level in blood stream may contribute with L.A. to provoke the high toxicity in the liver tissue. Furthermore the low serum testosterone level, which diminishes the level of androgen signaling in the liver, should have a negative effect on androgen control over some of the liver functions.

\subsection{Kidney}

This abnormalities in kidney is supported by the finding of [26], who showed that a strong association between lead exposure and renal effects included impairment of proximal tubular function manifests in aminoaciduria, glycosuria and hyperphosphaturia. It has been reported that L.A. causes mitochondrial damage, uncoupling of the respiratory chain and cell death [16]. Another histological indication of lead toxicity in the kidney is the karyomegaly of tubular cells [27]. Tubular, interstitial and glomerular damage are also characteristic renal lesions due to lead toxicity. Also the results of present study showed clear kidney degeneration associated with L.A. toxicity and characterized by varying degrees of damaged glomeruli, and degenerated tubules [28]. On another hand testosterone receptors are expressed on the surface of mesangial cells [29]. In addition, the androgens present proapoptotic and profibrotic properties [30]. Besides that testosterone seems to activate the renin-angiotensin system, resulting in sodium retention, higher blood pressure and renal injury [31]. Also testosterone increases collagen synthesis by vascular smooth muscle cells in culture. It has been suggested that some changes related to collagen may occur along with a significant reduction in the glomerular filtration rate in rats. Some metabolic alterations, including disorders in the secretion of hormones and the response of target tissues, causing several endocrine dysfunctions that contribute to worse outcomes [32] and [33]. Among those, hypogonadism (testosterone deficiency) is the most common gonadal alteration in men, mainly because of reduced prolactin clearance [34] and uremic inhibition of luteinizing hormone signaling at the level of the Leydig cells [35].

\section{CONCLUSION}

The present study concluded that male rats were treated with L.A. produce degenerated characteristics in the liver and kidney tissues, by accumulation of both extra cellular and intracellular materials as a result of cellular metabolic disturbance and alterations in nuclear membrane in both groups. Meanwhile in the castrated rats (group I) the effect of L.A. was more intense than the non-castrated rats (group II) my return to the lack of testosterone. But further studies are needed to make clear association between androgens level and liver and kidney toxicity.

\section{REFERENCE}

[1] D. D. Chiras, Environmental science: Jones \& Bartlett Publishers, 2011.

[2] F. R. Moreira and J. C. Moreira, "Effects of lead exposure on the human body and health implications," Revista Panamericana de Salud Pública, vol. 15, pp. 119-129, 2004.

[3] D. R. Juberg, C. F. Kleiman, and S. C. Kwon, "Position paper of the American Council on Science and Health: lead and human health," Ecotoxicology and environmental safety, vol. 38, pp. 162-180, 1997.

[4] P. Hotz, F. Mujyabwami, H. Roels, A. M. Bernard, and R. R. Lauwerys, "Effect of oral protein load on urinary protein excretion in workers exposed to cadmium and to lead," American journal of industrial medicine, vol. 29, pp. 195-200, 1996.

[5] R. Patra, D. Swarup, and S. Dwivedi, "Antioxidant effects of $\alpha$ tocopherol, ascorbic 
acid and L-methionine on lead induced oxidative stress to the liver, kidney and brain in rats," Toxicology, vol. 162, pp. 81-88, 2001.

[6] E. Wielgus-Serafińska, A. Zawadzka, and B. Falkus, "The effect of lead acetate on rat liver mitochondria," Acta physiologica Polonica, vol. 31, pp. 659-668, 1979.

[7] B. M. Jarrar and N. T. Taib, "Histological and histochemical alterations in the liver induced by lead chronic toxicity," Saudi journal of biological sciences, vol. 19, pp. 203-210, 2012.

[8] U. Radwańska-Konarzewska, F. Woźniak, and Z. Siezieniewska, "Influence of lead acetate on the histological, ultrastructural and histochemical picture of the livers of albino rats," in Annales Universitatis Mariae CurieSklodowska. Sectio D: Medicina, 1992, pp. 141-147.

[9] K. Goswami, R. Gachhui, and A. Bandopadhyay, "Hepatorenal dysfunctions in lead pollution," Journal of environmental science \& engineering, vol. 47, pp. 75-80, 2005.

[10] M. H. Jankeer and A. A. El-Nouri, "Histological study of the liver and kidney of albino mice Mus musculus exposed to lead," $J$. Raf. Sci, vol. 20, pp. 42-51, 2009.

[11] Z. Haouas, A. Sallem, I. Zidi, H. Hichri, I. Mzali, and M. Mehdi, "Hepatotoxic effects of lead acetate in rats: histopathological and cytotoxic studies," Journal of Cytology \& Histology, vol. 5, p. 1, 2014.

[12] A. M. Hegazy and U. A. Fouad, "Evaluation of Lead Hepatotoxicity; Histological, Histochemical and Ultrastructural Study," Forensic Medicine and Anatomy Research, vol. 2, p. 70, 2014.

[13] R. Jabeen, M. Tahir, and S. Waqas, "Teratogenic effects of lead acetate on kidney," J Ayub Med Coll Abbottabad, vol. 22, pp. 7679, 2010.

[14] F. Hartgens and H. Kuipers, "Effects of androgenic-anabolic steroids in athletes," Sports medicine, vol. 34, pp. 513-554, 2004.

[15] C. Bukowski, M. A. Grigg, and C. Longcope, "Sex hormone-binding globulin concentration: differences among commercially available methods," Clinical chemistry, vol. 46, pp. 14151416, 2000.

[16] L. Wang, H. Wang, M. Hu, J. Cao, D. Chen, and Z. Liu, "Oxidative stress and apoptotic changes in primary cultures of rat proximal tubular cells exposed to lead," Archives of toxicology, vol. 83, pp. 417-427, 2009.

[17] Y. Verma and S. Rana, "Modulation of CYP $4502 \mathrm{E} 1$ and oxidative stress by testosterone in liver and kidney of benzene treated rats," 2008.

[18] M. P. Keane, J. A. Belperio, D. A. Arenberg, M. D. Burdick, Z. J. Xu, Y. Y. Xue, et al., "IFN- $\gamma$-inducible protein-10 attenuates bleomycin-induced pulmonary fibrosis via inhibition of angiogenesis," The journal of immunology, vol. 163, pp. 5686-5692, 1999.

[19] R. Drury and E. Wallington, "Preparation and fixation of tissues," Carleton's histological technique, vol. 5, pp. 41-54, 1980.

[20] J. D. Bancroft and M. Gamble, Theory and practice of histological techniques: Elsevier Health Sciences, 2008.

[21] M. Kosnett, "Heavy metal intoxication and chelators," Basic and clinical pharmacology, 10th ed, New York: McGraw-Hill, pp. 945-957, 2007.

[22] H. Ohkawa, N. Ohishi, and K. Yagi, "Assay for lipid peroxides in animal tissues by thiobarbituric acid reaction," Analytical biochemistry, vol. 95, pp. 351-358, 1979.

[23] A. A. El-Nekeety, A. A. El-Kady, M. S. Soliman, N. S. Hassan, and M. A. AbdelWahhab, "Protective effect of Aquilegia vulgaris (L.) against lead acetate-induced oxidative stress in rats," Food and chemical toxicology, vol. 47, pp. 2209-2215, 2009.

[24] G. H. El-Sokkary, G. H. Abdel-Rahman, and E. S. Kamel, "Melatonin protects against leadinduced hepatic and renal toxicity in male rats," Toxicology, vol. 213, pp. 25-33, 2005.

[25] P. Tanganelli, G. Bianciardi, L. Barbagli, A. Paffetti, A. Di Stefano, M. Pizzichini, et al., "Effects of testosterone on the liver of castrated rats: morphologic study," Experimental pathology, vol. 43, pp. 21-24, 1991.

[26] J. Buchet, R. Lauwerys, H. Roels, A. Bernard, P. Bruaux, F. Claeys, et al., "Renal effects of cadmium body burden of the general population," The Lancet, vol. 336, pp. 699-702, 1990.

[27] B. Payne and L. Saunders, "Heavy metal nephropathy of rodents," Veterinary pathology, vol. 15, pp. 51-87, 1978.

[28] A. Bateman, L. Coin, R. Durbin, R. D. Finn, V. Hollich, S. Griffiths-Jones, et al., "The Pfam protein families database," Nucleic acids research, vol. 32, pp. D138-D141, 2004.

[29] I. Z. Pawluczyk, E. K. Tan, and K. P. Harris, "Rat mesangial cells exhibit sex-specific profibrotic and proinflammatory phenotypes," Nephrology Dialysis Transplantation, vol. 24, pp. 1753-1758, 2009.

[30] P. D. Metcalfe, J. A. Leslie, M. T. Campbell, D. R. Meldrum, K. L. Hile, and K. K. Meldrum, "Testosterone exacerbates obstructive renal injury by stimulating TNF- $\alpha$ production and increasing proapoptotic and profibrotic signaling," American Journal of PhysiologyEndocrinology and Metabolism, vol. 294, pp. E435-E443, 2008.

[31] J. Hu, S. Tan, and Y. Zhong, "Effects of testosterone on renal function in salt-loaded rats," The American journal of the medical sciences, vol. 342, pp. 38-43, 2011.

[32] D. J. Handelsman, "Hypothalamic-pituitary gonadal dysfunction in renal failure, dialysis and renal transplantation," Endocrine Reviews, vol. 6, pp. 151-182, 1985.

[33] J. Carrero, A. Qureshi, J. Axelsson, M. Yilmaz, S. Rehnmark, M. Witt, et al., "Clinical and biochemical implications of low thyroid 
hormone levels (total and free forms) in euthyroid patients with chronic kidney disease," Journal of internal medicine, vol. 262, pp. 690701, 2007.

[34] A. Schmidt, A. Luger, and W. H. Hörl, "Sexual hormone abnormalities in male patients with renal failure," Nephrology Dialysis Transplantation, vol. 17, pp. 368-371, 2002.

[35] L. Dunkel, T. Raivio, J. Laine, and C. Holmberg, "Circulating luteinizing hormone receptor inhibitor (s) in boys with chronic renal failure," Kidney international, vol. 51, pp. 777784, 1997.

\section{ACKNOWLEDGMENTS}

We extend many thanks to the department of Biology, Faculty of science, Soran University, Iraq for its support, their providing funds and facilities necessary to achieve the desired goals of the research. 